\title{
Effect of Cornus officinalis glycosides on the myelin basic protein in blood serum and the nerve function in Balb/c mice after sciatic nerve injury
}

\author{
Feng Liang ${ }^{1}$, Suming $\mathrm{Wu}^{2}$ and Shuang $\mathrm{Qi}^{1, \mathrm{a}}$ \\ ${ }^{1}$ China-Japan Union Hospital of Jilin University \\ ${ }^{2}$ The $4^{\text {th }}$ Hospital of Jilin University(The General Hospital of FAW)
}

\begin{abstract}
Objective: to explore the effect of cornus officinalis glycosides(COG) on the myelin basic protein(MBP) in blood serum andthe nerve function in Balb/c mice after sciatic nerve injury.Methods : Adult male Balb/c mice were randomly divided into high-dose, middle-dose, low-dose COG groups,.Transecting and inosculating the right sciatic nerve; testing the concentration of MBP by ELISA in 3, 5 days, $1,2,4,8$ weeks and having electroneurophysiological detection in 4,8 and 12 weeks after surgery respectively; making statistical analysis of the results. .Results : The MBP concentration and results of lectroneurophysiological detection have clear dose-effect relationship with the COG dose. Conclusion: Through inhibiting the demyelination of the sciatic nerve, COG can lower the degree of nerve damage so that accelerating the nerve regeneration.
\end{abstract}

\section{Introduction}

The thesis applies COG to Balb/c mice with sciatic nerve injury and intends to provide theoretical foundation for the effects of COG on peripheral nerve injury through the fuctional determination of MBP and nerve electrophysiology.

\section{Materials and Methods}

\subsection{Animal Grouping and Molding}

848 -week healthy male Balb/c mice weighing $(20+2) \mathrm{g}$ were raised in the same condition. Injecting with anesthesia in abdominal cavity by $1 \%$ pentothal sodium $100 \mathrm{mg} / \mathrm{kg}$. The operating field was disinfected routinely. Oblique incision was performed on the right side of the hip; the muscle got blunt separation; the sciatic nerve was exposed. Completely cutting off the nerve trunk $0.5 \mathrm{~cm}$ under the ischial tuberosity; under 12-times surgical microscope, using 11-0 atraumatic suture needle to anastomose the lacerated ends; then closing the wound layer by layer. Randomly dividing the mice into high-dose COG group (320 mg/kg/d), middle-dose COG (160 mg/kg/d), low-dose COG group $(80 \mathrm{mg} / \mathrm{kg} / \mathrm{d})$ and normal saline control group with 16 cases in each group. Each group was

\footnotetext{
${ }^{a}$ Corresponding author: qishuang@jlu.edu.cn
} 
administrated the drug by gavage continuously till death. Observing the mice at 7 time points, namely 3 days, 5 days, 1 week, 2 weeks, 4 weeks, 8 weeks and 12 weeks after surgery.

\subsection{Detection of Related Indexes}

Using Medtronic Keypoint myoelectricity/evoked potential machine to test the bilateral sciatic nerves of mice 4 weeks, 8 weeks and 12 weeks after surgery. The indoor temperature was $24{ }^{\circ} \mathrm{C}$; using $1 \%$ pentothal sodium for intraperitoneal anesthesia; making routine disinfection on the surgical field; the prone position showed the sciatic nerve; stabbing the soleus of mice with pin needle electrode; the muscle belly was a recording spot (M); the grounding electrode was placed at the tails of mice. Performing parallel stimulating electrode (the fixed space between the two electric poles was $2 \mathrm{~mm}$ ) on the anastomotic stoma of the sciatic nerve near the ischial tuberosity level (P) and the branch of distal sciatic nerve (D) with strong stimulation(10mA electric current). Using coliper to measure and input the distance between the stimulating electrodes; then the instrument would calculate MNCV automatically. The formula is as follows:

$\mathrm{MNCV}=$ the distance between the two stimulating electrodes/latency difference value of the action potential.

Measuring the MBP of mice with ELISA method :According to time sequence, getting 3 mice from each group; drawing about $0.5 \mathrm{ml}$ eyeball blood; holding the blood with an Ep tube in $4^{\circ} \mathrm{C}$ refrigerator overnight after 2-hour standing in normal temperature. In the morrow, centrifuging the blood at the speed of $5000 \mathrm{r} / \mathrm{min}$ for $3 \mathrm{~min}$; taking the upper serum and storing it in $-20{ }^{\circ} \mathrm{C}$ refrigerator for standby application; having ELISA determination after the animal materials were obtained.

\subsection{Statistical Analysis}

Applying statistical software SPSS 13.0 for data analysis. The results of each group of samples were expressed by mean \pm standard deviation $(\bar{X} \pm S)$; using $\mathrm{t}$ to verify the contrast between administered groups as well as the contrast between administered groups and the control group; if $\mathrm{P}<0.05$, then the difference has statistical significance.

\section{Results}

comparing the MNCV of each COG group with the control group 4 weeks, 8 weeks, 12 weeks after surgery, the data got from each group has difference. Comparing different time points of high-dose group, middle-dose group and low-dose group respectively, significant differences exist while there was no significant difference between high-dose group and middle-dose group. The MNCV which was obtained 4 weeks, 8 weeks and 12 weeks after surgery is shown in table 1 .

The contrasting result of the MBP concentration in serum at each time point is shown in table 2 . Using $t$ to check the results of high-dose, middle-dose and low dose groups with the control group respectively. If $\mathrm{P}<0.05$, then there exist significant differences.

Table 1 Testing results of each group 4,8 and 12 weeks after surgery $(\bar{X} \pm S \mathrm{n}=3$ ), m/s

\begin{tabular}{cccc}
\hline Groups & 4 weeks after surgery & 8 weeks after surgery & 12 weeks after surgery \\
\hline $\begin{array}{c}\text { High-dose } \\
\text { group }\end{array}$ & $41.1 \pm 0.72^{\mathrm{abc}}$ & $63.9 \pm 1.64^{\mathrm{abc}}$ & $64.8 \pm 1.52^{\mathrm{abc}}$ \\
$\begin{array}{c}\text { Middle-dose } \\
\text { group } \\
\text { Low-dose } \\
\text { group }\end{array}$ & $37.4 \pm 0.93^{\mathrm{ab}}$ & $58.4 \pm 1.17^{\mathrm{ab}}$ & $59.7 \pm 0.83^{\mathrm{ab}}$ \\
Control & $33.8 \pm 0.79^{\mathrm{a}}$ & $52.6 \pm 0.79^{\mathrm{a}}$ & $54.1 \pm 0.39^{\mathrm{a}}$ \\
\hline
\end{tabular}


group

Comparing each COG groups with the control group, ${ }^{\mathrm{a}} 0.01<\mathrm{P}<0.05$; comparing high-dose and middle-dose groups with low-dose group, ${ }^{\mathrm{b}} 0.01<\mathrm{P}<0.05$; comparing high-dose group with middle-dose group, ${ }^{\mathrm{c}} \mathrm{P}>0.05$

Table 2 The comparison results of the MBP concentration in serum at different time points

$$
\left(\bar{X} \pm S_{\mathrm{n}=3), \mathrm{ng} / \mathrm{l}}\right.
$$

\begin{tabular}{ccccc}
\hline Time points & High-dose group & Middle-dose group & Low-dose group & Control group \\
\hline 3d after surgery & $6984 \pm 330.2^{\mathrm{a}}$ & $7625 \pm 209.5^{\mathrm{b}}$ & $8329 \pm 207.4^{\mathrm{c}}$ & $9657 \pm 323.5$ \\
5d after surgery & $6119 \pm 75.9^{\mathrm{a}}$ & $6550 \pm 199.2^{\mathrm{b}}$ & $7441 \pm 175.2^{\mathrm{c}}$ & $8752 \pm 206.1$ \\
1w after surgery & $4812 \pm 142.7^{\mathrm{a}}$ & $5402 \pm 124.6^{\mathrm{b}}$ & $6035 \pm 114.3^{\mathrm{c}}$ & $7821 \pm 245.2$ \\
2w after surgery & $3084 \pm 122.3^{\mathrm{a}}$ & $3815 \pm 110.9^{\mathrm{a}}$ & $4723 \pm 109.1^{\mathrm{b}}$ & $6836 \pm 122.4$ \\
4w after surgery & $1665 \pm 140.8^{\mathrm{a}}$ & $1987 \pm 76.5^{\mathrm{a}}$ & $2196 \pm 96.1^{\mathrm{b}}$ & $2456 \pm 82.6$ \\
8w after surgery & $1422 \pm 66.0 \mathrm{a}$ & $1596 \pm 63.2 \mathrm{a}$ & $1822 \pm 72.3 \mathrm{~b}$ & $2108 \pm 77.6$ \\
\hline
\end{tabular}

Comparing the data of each COG groups with the control group, ${ }^{\mathrm{a}} \mathrm{P}<0.01,{ }^{b} 0.01<\mathrm{P}<0.05,{ }^{\mathrm{c}} \mathrm{P}>0.05$.

\section{Discussion}

COG is a kind of traditional Chinese medicine with multiple effects such as immunosuppression, antidiabetic, anti-inflammatory effect, oxidation resistance, antiarrhythmic effect, etc[1]. In recent years, many studies show that COG can significantly increase the number of newborn mature neurons and blood vessels of mice with cerebral injury and improve their nervous system functions[2]; but there has no report about its impact on nerve regeneration and repairing after peripheral nerve injury.

The majority of peripheral nerves are medullated nerves. The regeneration and repairing of myelin sheath has close relationship with the regeneration of nerve fibers. MBP is the main protein of myelin sheath and it has neural specificity. Under normal physiological condition, its content in serum is extremely low[3-4]. After peripheral nerve injury, the parclose between nervus vascularis is damaged and the expression quantity of MBP in blood volume increases rapidly, so the different expressions of MBP can dynamically observe the situation of myelin damage and repairing[5].

This experiment adopted ELISA method to detect the MBP concentration in the sciatic nerve and serum. The experimental results show that in the early and middle stage of nerve repairing, the MBP concentration of COG groups is lower than the control group and there exist significant differences, which means that COG can effectively reduce the demyelination degree of sciatic nerve in nerve regeneration. The testing results of nerve electrophysiology suggest that the MNCV of each group increases continuously over time and the MNCV of COG groups has great advantage over the control group in each time point. It shows that COG can lower the expression of MBP in serum to reduce the disintegration of myelin sheath and axon so as to protect the myelin sheath and promote the repairing of injured sciatic nerve.

In brief, COG can accelerate the regeneration myelin sheath and axon of the injured sciatic nerve. Its mechanism may be inhibiting the expression of MBP in serum to reduce partial damage level of injured nerves so as to accelerate the nerve regeneration.

\section{References}

1. Miao Y, Xiaoxian W, Military Medical Journal of Southeast China,12,240(2010)

2. Yao RQ,Zhang L,Wang W, Brain Res Bull, 79,69, (2009)

3. Min Y,Kristiansen K,Boggs J M, Proceedings of the National Academy of Sciences, 106,315, (2009) 
4. Tompa P,FEBS letters,579,3346 (2005)

5. Brettschneider J, Petzold A, Sussmuth S,Journal of neurology, 256,3(2009) 